\title{
Pharmaceutical Quality/CMC Testing Site Unique Identifier Terminology
}

National Cancer Institute

\section{Source}

National Cancer Institute. Pharmaceutical Quality/CMC Testing Site Unique Identifier

Terminology. NCI Thesaurus. Code C133869.

A category of terminology used to qualify the information pertaining to testing site unique identifiers in the framework of the Pharmaceutical Quality/Chemistry, Manufacturing and Controls documents. 